Về vị trí xuất hiện của răng cối lớn thứ nhất hàm dưới ba chân, kết quả nghiên cứu của chúng tôi gần giống kết quả của một số nghiên cứu khác cho rằng $\mathrm{RCL}$ thứ nhất hàm dưới ba chân xuất hiện ở bên phải nhiều hơn bên trái. Sự khác biệt về kết quả này có thể được giải thích do sự khác nhau trong cách chọn mẫu và phương pháp nghiên cứu tùy theo từng tác giả.

Các nhà lâm sàng cần lưu ý khi điều trị nội nha chân răng xa trong ở $\mathrm{RCL}$ thứ nhất hàm dưới để giảm nguy cơ đi sai hướng, tạo khấc, thủng ống tủy, gãy dụng cụ và đưa dụng cụ đi quá chóp trong quá trình sửa soạn ống tủy.

Lối mở vào tủy hình tam giác thường dùng cho RCL thứ nhất hàm dưới cần phải được biến đổi thành lối vào tủy có dạng hình thang để có thể định vị ống tủy xa trong và tất cả những ống tủy hiện diện trên RCL thứ nhất hàm dưới có ba chân.

Thường phải tạo đường vào trơn tru (glide path) từ trâm số nhỏ nhất, chọn trâm có độ đàn hồi cao như trâm NiTi và sửa soạn thật chậm rãi, cẩn thận. Nếu vội vàng thì nguy cơ cao sẽ bị lạc đường, tạo khấc, tắc ống tủy và thậm chí là gã̃y dụng cụ ở dưới đoạn gập góc, khả năng lấy ra được rất thấp và để lách qua đoạn trâm gãy cũng rất khó. Ống tủy cong một phần hoặc cong toàn bộ của chân răng xa trong này làm tăng nguy cơ gãy trâm ở bất kỳ đoạn nào của ống tủy trong quá trình sửa soạn ống tủy.

\section{KẾT LUẬN}

Tỉ lệ răng cối lớn thứ nhất hàm dưới trên ConeBeam CT có hai chân chiếm đa số. Đây là đặc điểm làm cơ sở cho các thầy thuốc trong điều trị nội nha.

\section{TÀI LIỆU THAM KHẢO}

1. Nguyễn Cẩn, Ngô Đồng Khanh. (2007), "Phân tích dịch tễ bệnh sâu răng và nha chu ở Việt Nam". Tạp chí Y học Thành phố Hô Chí Minh, 11(3), 144-149.

2. de Pablo O. V., Estevez R., Peix Sanchez M., et al. (2010), "Root anatomy and canal configuration of the permanent mandibular first molar: a systematic review". J Endod, 36(12), 1919-1931.

3. Chen Y. C., Lee Y. Y., Pai S. F., et al. (2009) "The morphologic characteristics of the distolingual roots of mandibular first molars in a Taiwanese population". J Endod, 35(5), 643-645.

4. Curzon M. E. (1974), "Miscegenation and the prevalence of three-rooted mandibular first molars in the Baffin Eskimo". Community Dent Oral Epidemiol, 2(3), 130-131.

5. Gulabivala K., Opasanon A., Ng Y. L., et al. (2002), "Root and canal morphology of Thai mandibular molars". Int Endod J, 35(1), 56-62.

6. Schafer E., Breuer D. ,Janzen S. (2009), "The prevalence of three-rooted mandibular permanent first molars in a German population". J Endod, 35(2), 202-205.

7. Ishii Namiko, Sakuma Ayaka, Makino Yohsuke, et al. (2016), "Incidence of threerooted mandibular first molars among contemporary Japanese individuals determined using multidetector computed tomography". Legal Medicine, 22, 9-12.

8. Serene T. P. ,Spolsky V. W. (1981), "Frequency of endodontic therapy in a dental school setting". J Endod, 7(8), 385-387.

\title{
HIÊ̂U QUẢ ĐIỀU TRI TRIÊTT CĂN BẰNG XẠ TRI ĐIỀU BIẾN LIỀU ĐồnG THỜI VỚI HÓA CHẤT PHÁC ĐỒ FOLFOX CHO BỆNH NHÂN UNG THƯ THỰC QUẢN
}

\author{
Dương Thùy Linh'1, Phạm Thị Mai ${ }^{1}$, Trần Văn Tôn ${ }^{1}$, \\ Lại Thị Định ${ }^{1}$, Nguyễn Vắn Ba ${ }^{1}$, Trần Viết Tiến ${ }^{1}$
}

\section{TÓM TẮT}

Mục tiêu: Đánh giá hiệu quả xạ trị điều biến liều hóa xạ đồng thời với phác đồ FOLFƠx điều trịtriệt căn ung thư thực quản. Đối tượng và phương pháp: Nghiên cứu mô tả tiến cứu 32 bệnh nhân ung thư thực quản giai đoạn cT2-4N+M0 hóa xa trị đông thời triệt căn với kĩ thuật xạ trị điều biến liều tại khoa Vật lý xạ trị - Trung tẩm Üng bướu - Bệnh viện Quân Y

${ }^{1}$ Bệnh viện Quân y 103

Chịu trách nhiệm chính: Dương Thùy Linh

Email: bsduonglinh103@gmail.com

Ngày nhận bài: 7/3/2021

Ngày phản biên khoa học: 4/4/2021

Ngày duyệt bài: 2/5/2021
103- Hoc viên Quân $Y$ từ T1/2018 - T6/2020. Kết quả: Bểnh nhân chủ yếu là nam giới, tuổi hay gặp 40 - 59 tuổi. Mô bênh học $100 \%$ là ung thư biểu mồ vảy, $50 \%$ là ung thư biểu mô vảy biệt hóa vừa. Cách phân liều: $66 \mathrm{~Gy} / 30 \mathrm{fx}$ chiếm tỉ lệ $25 \%, 60 \mathrm{~Gy} / 28 \mathrm{fx}$ chiếm tỉ lê $75 \%$. Hóa chất phác đồ FOLFOX đủ liều chiếm tỉ lệ $71,9 \%$, giảm liều chiếm tỉ lệ $28,1 \%$. Đánh giá đáp ứng trên $\mathrm{CT}$ : đáp ứng hoàn toàn chiếm $56,2 \%$, đáp ứng một phần chiếm tỉ lệ $34,4 \%$, không đáp ứng 9,4\%. Biến chứng trên hệ tạo máu: thiếu máu(34,4\%), giảm bach câu $(21,9 \%)$, giảm tiểu cầu $(15,6 \%)$. Biến chứng viêm thực quản $90,6 \%$, viêm da $56,2 \%$ chủ yếu độ 1 , độ 2. Kết luân: Điều trị triệt căn ung thư thực quản bắng phác đồ hóa xạ trị đồng thời với kĩ thuật xạ trị điều biến liêu kết hợp hóa chất phác đồ FOLFOX cho kết quả đáp ứng tốt, tỉ lệ độc tính trong giới hạn chấp 
nhận được.

Tư khóa: Ung thư thực quản, xạ trị điều biến liều, hóa xạ trị đồng thời.

\section{SUMMARY}

\section{RESULTS OF INTENSITY MODULAED} RADIATION THERAPY TECHNIQUE COMBINE WITH CHEMOTHERAPY FOLFOX FOR ESOPHAGEAL CANCER PATIENTS

Background: This study aims to evaluate some patient's characteristics and treatment outcome of concurrent chemoradiation therapy with intensity modulated radiation therapy (IMRT) technique in esophageal cancer patients. Materials and methods: A descriptive perspective study with 32esophageal cancer patients treated by concurrent chemoradiation therapy with IMRT using simultanous intergrated technique in Department of Radiation oncology, Oncology Center, 103 Military Hospital from 2018 to June 2020. Result: Disease are most seen in men, age $40-59$ years old. Most of patients are late stage with $100 \%$ histopathology is squamous cell cancer in moderately differentiation acounted for $50 \%$. Radiation schedules were $66 \mathrm{~Gy} / 30 \mathrm{fx}$ and $60 \mathrm{~Gy} / 28 \mathrm{fx}$ in $25 \%$ and $75 \%$, respectively. Chemo regimens were Oxaliplatin $85 \mathrm{mg} / \mathrm{m} 2$ day 1 , Leucovorin $400 \mathrm{mg} / \mathrm{m} 2$ day 1 and Fluorouracil $400 \mathrm{mg} / \mathrm{m} 2$ bolus day 1 , Fluorouracil $1600 \mathrm{mg} / \mathrm{m} 2$, 46 hous, every 14 days.Full dose chemotherapy was given in $71,9 \%$. Common toxicities were low hematological toxicity, esophagitis $(90,6 \%)$ and dermatis $(56,2 \%)$. Most of them were grade 1,2. Conclusions: Concurrent chemoradiation with IMRT technique and FOLFOX in esophageal cancer patient had promising results and well tolerence.

Keywords: Esophageal cancer, concurrent chemoradiotherapy, intensity modulated radiation therapy.

\section{I. ĐẶT VẤN ĐỀ}

Ung thư thực quản là bệnh lý ác tính đứng thứ 7 trong nhóm các bệnh có tỉ lệ mới mắc cao nhất ( 572.000 ca mới mắc) và có tỉ lệ tử vong cao đứng thứ 6 trong các bệnh ung thư (509.000 ca tử vong). Với những tiến bộ trong chẩn đoán tỷ lệ ung thư thực quản ở giai đoạn muộn đã giảm đáng kể, tuy nhiên kết quả điểu trị còn nhiêu hạn chế không chỉ ở Việt Nam mà còn ở các nước phát triển với tỷ lệ tử vong hàng năm còn cao [1]. Ở Việt Nam, ung thư thực quản nằm trong số 10 loại ung thư phổ biến nhất ở nam giới, riêng ở Hà Nội thì ung thư thực quản đứng ở vị trí thứ 5 , với tỷ lệ mắc 8,7 trên 100.000 nam giới.

Các phương pháp chính điều trị ung thư thực quản gồm phẩu thuật, xạ trị và hóa chất phụ thuộc vào vị trí khối u, giai đoạn bệnh, và thể trạng người bệnh. Với ung thư thực quản giai đoạn không phẫu thuật được thì hóa xạ trị đồng thời được xem là xu thế chung trong phác đồ điêu trị trên thế giới.

Tuy nhiên, các kỹ thuật xạ trị thông thường (2D, 3D) có khả năng kiểm soát khối u còn hạn chế và nguy cơ cao gây tác dụng phụ cho bệnh nhân. Xạ trị điêu biến liều là kỹ thuật xạ trị tiên tiến với khả năng tối ưu liều xạ trị vào u, phân bố liều lượng khác nhau đồng thời vào các vùng thể tích, giảm liều vào các cơ quan lành xung quanh như tim, phổi, tủy sống, cơ vùng họng, do đó có thể khắc phục được các nhược điểm của các kỹ thuật xạ trị thông thường. Hiện nay có nhiều phác đồ HXTĐT khác nhau: Cisplatin/5-FU kết hợp đồng thời xạ trị ngoài là phổ biến, một số trường hợp vì những lý do khác nhau không điều trị được phác đồ Cisplatin/5-FU, có thể dùng phác đồPalitaxel - Carboplatin như một sự thay thế hợp lý [2]. Gần đây, phác đồ FOLFOX được đưa vào thử nghiệm kết hợp đồng thời với xạ trị, cho thấy khả năng dung nạp tốt và hiệu quả tương đương với phác đồ Cisplatin/5-FU [3]. Theo khuyến cáo của NCCN (National Comperhensive Cancer Network) từ năm 2015 đến nay thì HXTĐT phác đồ FOLFOX đang là một trong những lựa chọn hàng đầu [4].

Hiện tại, ở Việt Nam chưa có nghiên cứu đánh giá hiệu quả hóa xạ trị đồng thời triệt căn với phác đồ hóa trị FOLFOX. Vì vậy, chúng tôi tiến hành nghiên cứu: "Hiệu quả hóa xạ trị đồng thời triệt căn xạ trị điều biến liều kết hợp hóa trị phác đồ FOLFOX điều trị ung thư thực quản"

Số liệu của bài báo là một phần kết quả nghiên cứu của đề tài cấp Nhà nước

"Nghiên cứu ứng dụng kỹ thuật $\mathrm{PET} / \mathrm{CT}$ và sinh học phân tử trong chẩn đoán và điều trị ung thư thực quản. Mã số KC.10./16-20"

\section{II. ĐỐI TƯƠNG VÀ PHƯƠNG PHÁP NGHIÊN CỨU}

2.1. Đối tượng nghiên cứu. 32 bệnh nhân ung thư thực quản có chỉ định điêu trị hóa xạ trị đồng thời triệt căn với kĩ thuật xạ trị điều biến liều và hóa chất phác đồ FOLFOX tại khoa Vật lý xạ trị - Trung tâm Ung bướu - Bệnh viện Quẩn Y 103 từT1/2018 - T6/2020.

Tiêu chuẩn lựa chọn

- Bệnh nhân chẩn đoán xác định bằng mô bệnh học là ung thư biểu mô vảy, giai đoạn CT2$4 \mathrm{~N}+\mathrm{MO}$ dựa vào phân loại giai đoạn năm 2017 của Hội ung thư Mỹ có chỉ định hóa xạ trị đồng thời triệt căn.

- Tuổi >18; Điểm toàn trạng ECOG <=2.

- Chức năng gan, thận, công thức máu ngoại vi trong giới hạn bình thường.

\section{Tiêu chuẩn loai trừ}

- Phụ nữ đang mang thai hoặc cho con bú 
- Có bệnh nặng kết hợp.

\subsection{Phương pháp nghiên cứu}

Thiết kế nghiên cứu: Mô tả tiến cứu và theo dõi dọc.

Phương pháp tiến hành. Bệnh nhân được khám lâm sàng, làm một số xét nghiệm thường quy, nội soi sinh thiết làm giải phẩu bệnh, chụp CT, PET/CT đánh giá giai đoạn dựa vào phân loại giai đoạn năm 2017 của Hội ung thư Mỹ. Điều trị triệt cắn hoá xạ trị đồng thời với phác đồ Oxaliplatin - 5FU x 6 chu kì Oxaliplatin $85 \mathrm{mg} / \mathrm{m} 2$ diện tích da cơ thể, truyền tĩnh mạch ngày 1 ; Leucovorin: $400 \mathrm{mg} / \mathrm{m} 2$, tĩnh mạch, ngày 1 , 5FU: $400 \mathrm{mg} / \mathrm{m} 2$, tiêmbolus tĩnh mạch, ngày $1 ; 5$ FU $1600 \mathrm{mg} / \mathrm{m} 2$, truyền tĩnh mạch liên tục trong 46h, ngày 1,2 , chu kì 14 ngày, 3 chu kì đầu

\section{KẾT QUẢ NGHIÊN CỨU VÀ BÀN LUÂN}

\section{1. Đặc điểm lâm sàng và cận lâm sàng UTTQ}

Bảng 3.1. Đặc điểm chung ( $n=32)$

\begin{tabular}{|c|c|c|c|c|c|c|}
\hline Tuối & 53,75 & $(39-67)$ & Sin & hiết SCC & 32 & $100 \%$ \\
\hline Giới: & $\begin{array}{l}31 \\
01\end{array}$ & $\begin{array}{c}96,9 \% \\
3,1 \%\end{array}$ & PS: & $\begin{array}{l}0 \\
1 \\
\end{array}$ & $\begin{array}{l}09 \\
23\end{array}$ & $\begin{array}{l}28,1 \% \\
71,9 \% \\
\end{array}$ \\
\hline $\begin{array}{c}\text { Triệu chứng: Nuốt nghẹn } \\
\text { Đau ngực } \\
\text { Hạch cố } \\
\text { Khàn tiếng } \\
\text { Sút cân }\end{array}$ & $\begin{array}{l}32 \\
11 \\
08 \\
05 \\
28\end{array}$ & $\begin{array}{l}100 \% \\
34,4 \% \\
25,0 \% \\
15,6 \% \\
87,5 \% \\
\end{array}$ & cT & $\begin{array}{l}3 \\
4 a \\
4 b\end{array}$ & $\begin{array}{l}19 \\
11 \\
02\end{array}$ & $\begin{array}{l}59,4 \% \\
34,4 \% \\
6,2 \%\end{array}$ \\
\hline $\begin{array}{r}\text { Độ mô học: Độ } 1 \\
\text { Độ } 2 \\
\text { Độ } 3\end{array}$ & $\begin{array}{l}02 \\
16 \\
14\end{array}$ & $\begin{array}{c}6,2 \% \\
50 \% \\
43,8 \%\end{array}$ & CN: & $\begin{array}{l}0 \\
1 \\
2 \\
3 \\
\end{array}$ & $\begin{array}{l}01 \\
14 \\
14 \\
03 \\
\end{array}$ & $\begin{array}{c}3,1 \% \\
43,8 \% \\
43,8 \% \\
9,3 \% \\
\end{array}$ \\
\hline
\end{tabular}

Có 32 bệnh nhân đủ tiêu chuẩn điều trị hóa xạ đồng thời triệt căn với kĩ thuật xạ trị điều biên liều. Các bệnh nhân đủ tiêu chuẩn tham gia nghiên cứu đều là nam giới, có tuổi trung bình là 53,7 và chủ yếu PS là 1 . Các triệu chứng chủ quan gồm nuốt nghẹn (100\%), đau ngực $(34,4 \%)$ và sút cân $(87,5 \%)$. Kết quả nội soi sinh thiết $100 \%$ là ung thư biểu mô vảy chủ yếu là độ mô học 2-3 $(93,8 \%)$. Về phân loại giai đoạn u và̀ hạch, có 19 bệnh nhân $(59,4 \%)$ ở giai đoạn T3, 11 bệnh nhân ở giai đoạn T4a (34,4\%); 2 bệnh nhân giai đoạn T4b; tỉ lệ di căn hạch N1, N2 cao như nhau là $43,8 \%$, di căn hạch N3 chiếm 9,3\%, có duy nhất 1 bệnh nhân không di căn hạch $(3,1 \%)$. Đặc điểm này cho thấy bệnh UTTQ thường phát hiện ở giai đoạn muộn.

3.2. Đặc điểm phương phảp điêu trị hóa xạ đồng thời với IMRT

Bảng 3.2. Đặc điểm phương pháp điều trị

\section{Số chu kì hóa chất}

$>80 \%$ liều

$\leq 80 \%$ liều

\begin{tabular}{l|l}
23 & $71,9 \%$ \\
09 & $28,1 \%$ \\
\hline
\end{tabular}

đồng thời với xạ trị. Xạ trị điều biến liều với liều dự phòng hạch cố và trung thất 50.4 Gy (1.8 Gy/ngày), liều u và hạch nguyên phát 60 - 66 Gy. Tổng phân liều 28 - 33 buổi. Đánh giá đáp ứng tại thời điểm nghỉ 4 tuần sau khi kết thúc điều trị dựa vào tiêu chuẩn đánh giá đáp ứng dành cho các khối u đặc Response Evaluation Criteria in Solid Tumor (RECIST 1.1) trên CT và nội soi.Đánh giá độc tính theo tiêu chuẩn Terminology Criteria for Adverse Events (CTCAE v5.0) của viện Ung thư quốc gia Hoa Kì năm 2017. Đánh giá các biến chứng do xạ trị theo phân độ tổ chức xạ trị ung thư quốc tế (RTOG). Số liệu được nhập, lưu trữ và xử lý thống kê bằng phần mềm SPSS 20.0.

\begin{tabular}{|c|c|}
\hline \multicolumn{2}{|c|}{ Liêu vào u, hạch nguyên phát } \\
\hline $60 \mathrm{~Gy} / 2824$ & $75,0 \%$ \\
\hline $\begin{array}{l}\text { Trong quá trình điêê } \\
\text { phải giảm liều hóa chấ } \\
\text { và xạ trị không cho ph } \\
\text { đâu. } 25 \% \text { bệnh nhân } \\
\text { và hạch nguyên phát, } \\
\text { vào ù và hạch nguyêr } \\
\text { phòng liều } 50,4 \text { Gy (1, } \\
\text { Bảng 3.3. Các tha } \\
\text { xạ trị IMRT }\end{array}$ & $\begin{array}{l}\text { 28,1\% bệnh nhân } \\
\text { c tính của hóa chất } \\
\text { trì liều điêu trị ban } \\
\text { ng liêu } 66 \mathrm{~Gy} \text { vào u } \\
\text { được xạ trị } 60 \mathrm{~Gy} \\
100 \% \text { xạ hạch dự } \\
\text { ày). } \\
\text { liên quan kế hoạch }\end{array}$ \\
\hline $\begin{array}{r}\text { Các tiêu chí lập } \\
\text { Liều tủy cực đại (Gy) } \\
\text { Liều phổi trung bình (G } \\
\text { V20 phổi (\%)19,76 } \\
\text { Liêuu tim trung bình (Gy } \\
\text { V30 tim (\%)7,7 }\end{array}$ & $\begin{array}{l}\text { ach xa trị } \\
24,5 \mathrm{Max} \leq 45 \\
\pm 2,6 \mathrm{Mean} \leq 12 \\
2 \quad \text { V20 } \leq 20 \\
\pm 12,9 \text { Mean } \leq 30 \\
\text { V30 } \leq 30\end{array}$ \\
\hline $\begin{array}{l}\text { Các thông sô } \\
\text { Chiều dài u } \\
\text { Thể tích GTV } \\
\text { Thể tích PTV } 60-66\end{array}$ & $\begin{array}{l}\text { kế hoạch } \\
6,4 \pm 2,64 \\
37,01 \pm 27,44 \\
102,6 \pm 40,2\end{array}$ \\
\hline
\end{tabular}




\begin{tabular}{|cc|}
\hline Thể tích PTV 50,4 & $508,04 \pm 92,8$ \\
Số trường chiếu & $6,06 \pm 0,98$ \\
\hline
\end{tabular}

Kế hoạch xa trị điều biến liều với hai thể tích lập kế hoạch là PTV 50,4 và PTV $60-66 \mathrm{~Gy}$. Thể tích PTV 50,4 tương ứng với điều trị dự phòng di căn hạch cổ thấp và hạch trung thất nhận liêu 50,4 Gy, thể tích PTV $60-66$ Gy tương ứng u và hạch di căn đại thể nhận liều 60 - 66 Gy. Kế hoach IMRT sử dụng kĩ thuât nâng liều đồng thời tại các vùng thể tích (IMRT - SIB simultaneous intergrated boost) cho thấy sự ưu việt về phân bố liều cùng lúc về phân liều thấp 1,8 Gy/ngày với vùng thể tích dự phòng và phân liều cao 2,14 - 2.35 Gy/ngày cho vùng thể tích u và hạch nguyên phát. Do đó, điều trị với kĩ thuật IMRT SIB cho thây những ưu điểm đáng kể về khả năng phân bố liều tối đa vào các vùng thể tích và đảm bảo liều giới hạn cho phép với các cơ quan lành. Trong nghiên cứu của chúng tôi, chiều dài $u$ trung bình là $6,4 \mathrm{~cm}$, thể tích trung bình của PTV 50,4 là $508 \mathrm{~cm} 3$ và PTV 60-66 là 102,6 cm3 đều khá lớn, số trường chiếu xạ trung bình là 6,06 cao hơn số trường chiếu của xạ trị 3D lớn nhất là 5 trường chiếu và các tiêu chí cơ quan lành đảm bảo nhận liều ở ngưỡng thấp đặc biệt là tim và phổi. Đây chính là những ưu điểm của xạ trị điều biến liều mà kĩ thuật xạ trị 3D thường quy khó có thể đạt được. Tương tự, trong nghiên cứu của Haefner và cộng sự (2017) với 37 bệnh nhân UTTQ cổ ngực giai đoạn III hóa xạ điều biến liều triệt căn với thể tích trung bình PTV 50,4 là $796 \mathrm{~cm} 3$, thể tích trung bình PTV 60 - 66 Gy là $192 \mathrm{~cm} 3$, liều vào phổi trung bình là $12,2 \mathrm{~Gy}$, liều vào tim trung bình 14,2 Gy, liều vào tủy trung bình là $35,1 \mathrm{~Gy}$, đồng thời nghiên cứu cũng chỉ ra sự giảm liều đáng kể vào tủy và tim khi so sánh giữa hai nhóm bệnh nhân được xạ trị $3 D(n=49)$ và IMRT $(n=44)$, liều trung bình vào phổi (MLD) cũng được cải thiện cả với những thể tích PTV lớn khi được xạ trị IMRT [5].

3.3. Hiệu quả hóa xạ trị đồng thời với IMRT Bảng 3.4. Đáp ứng sau hóa xạ trị

\begin{tabular}{|c|c|c|c|}
\hline & $\begin{array}{c}\text { Không } \\
\text { đáp ứng }\end{array}$ & Một phân & Hoàn toàn \\
\hline Nội soi & $3(9,4 \%)$ & $9(28,1 \%)$ & $20(62,5 \%)$ \\
\hline CT & $3(9,4 \%)$ & $11(34,4 \%)$ & $18(56,2 \%)$ \\
\hline
\end{tabular}

Để đánh giá đáp ứng sau điêu trị hóa xạ trị đồng thời, chúng tôi đánh giá ở thời điểm sau khi kết thúc điều trị 1 tháng, dựa vào đáp ứng của khối u thực quản thông qua nội soi thực quản dạ dày, cắt lớp vi tính cổ ngực có tiêm và uống thuốc cản quang. Kết quả tại bảng 3.4 cho thây hiệu quả điều trị cho 32 bệnh nhân UTTQ được hóa xạ trị đồng thời triệt căn. Trên hình ảnh nội soi thực quản, $90,6 \%$ đáp ứng chung trong đó $62,5 \%$ đáp ứng toàn bộ. Đánh giá trên CT dựa vào tiêu chuẩn RECIST 1.1 tỷ lệ đáp ứng chung và đáp ứng toàn bộ tương ứng là $90,6 \%$, $56,2 \%$. Kết quả này cao hơn so vớikết quả trong nghiên cứu của Nguyễn Đức Lợi [6] trên 132 bệnh nhân UTTQ hóa xạ đồng thời sử dụng phác đồ 5FU - Cisplatin kết hợp xạ trị 3D 60Gy có tỉ lệ đáp ứng chung là $84,9 \%$ trong đó đáp ứng hoàn toàn là $31,1 \%$, không đáp ứng là $12,9 \%$. Kết quả của chúng tôi tương đương với kết quả nghiên cứu của tác giả Makoto Ito và cộng sự (2017), nghiên cứu trên 80 bệnh nhân UTTTQ cổ ngực trong đó có 32 bệnh nhân xạ trị IMRT và 48 bệnh nhân xa trị 3D - CRT kết hợp hóa chất cho thấy tỉ lệ đáp ứng hoàn toàn, đáp ứng một phần, không đáp ứng ở hai nhóm lần lượt là $75 \%, 15,6 \%, 9,4 \%$ và $68,8 \%, 22,9 \%, 8,3 \%$ [6].

3.4 Tác dung phu sau hóa-xa tri ở BN UTTQ Bảng 3.5. Tác dụng phụ sau hóa xạ trị

\begin{tabular}{|c|c|c|cc|}
\hline \multirow{2}{*}{ Tác dụng phụ } & \multicolumn{3}{|c|}{ Mức độ tốn thương (\%) } \\
\cline { 2 - 5 } & 0 & 1 & 2 & $3-4$ \\
\hline Buồn nôn, nôn & 34,4 & 56,2 & 9,4 & 0 \\
\hline Viêm thực quản & 9,4 & 50,0 & 37,5 & 3,1 \\
\hline Viêm da & 43,8 & 34,4 & \multicolumn{1}{|c|}{18,8} & 3,1 \\
\hline Viêm phổi & 81,2 & 9,4 & \multicolumn{2}{|c|}{$6,23,1$} \\
\hline Rò thực quản & 96,9 & 0 & 0 & 3,1 \\
\hline Hạ bạch cầu & 78,1 & 12,5 & \multicolumn{2}{|c|}{$3,16,2$} \\
\hline Hạ tiểu câuu & 84,4 & 9,4 & 6,2 & 0 \\
\hline Giảm huyết sắc tố & 65,6 & 21,9 & 12,5 & 0 \\
Tăng men gan & 84,4 & 15,6 & 0 & 0 \\
Tăng creatinin & 93,8 & 6,2 & 0 & 0 \\
\hline
\end{tabular}

Kết quả bảng 3.5 cho thấy các độc tính sau hóa xạ trị đồng thời ở bệnh nhân UTTQ. Các độc tính thường gặp nhất do xạ trị là viêm da, viêm thực quản với tỷ lệ độ $1-\dot{2}$ là $52,2 \%$ và $90,6 \%$, độ 3 - 4 là $3,1 \%$. Các biến chứng viêm phổi, rò thực quản có tỷ lệ thấp hơn. Các độc tính trên hệ tạo huyết gồm giảm bạch cầu, giảm tiểu cầu, giảm huyết sắc tố, độc tính tăng men gan, tăng creatinin đều ở mức độ $1-2$, có thể cải thiện được bằng điều trị nội khoa. Các bệnh nhân có độc tính độ $3-4$ chiểm $18,6 \%$ trong đó chủ yếu là hạ bạch câu $(n=2)$, viêm thực quản $(n=1)$, viêm da $(n=1)$, rò thực quản $(n=1)$. Các tác dụng phụ trong hóa xạ trị đều có thể được cải thiện nhưng đòi hỏi phải được theo dõi sát và điều trị kịp thời thì mới có thể đảm bảo cho bệnh nhân có thể điều trị đúng thời gian và đầy đủ liệu trình. Trong nghiên cứu PRODIGE 5/ ACCORD 17 (nghiên cứu phase 3 NCT 00861094), nghiên cứu so sánh độc tính giữa hai nhóm bệnh nhân ung thư thực quản không có 
khả năng phẫu thuât. 131 bênh nhân hóa xa trị đồng thời với phác đồ FOLFOX, 128 bệnh nhân hóa xạ trị đồng thời với phác đồ $C F$, nhận thây tất cả các biến cố độc tính nghiêm trọng xảy ra trên $5 \%$ bệnh nhân ở cả 2 nhóm, nhưung độc tính độ 3-4 giữa 2 nhóm sự khác biệt không có ý nghĩa thống kê. Các triệu chứng như chán ăn, độc tính thần kinh, tăng men gan xảy ra tỉ lệ cao hơn ở nhóm điều trị FOLFOX, các triệu chứng tăng creatinin, rụng tóc, viêm niêm mạc, tỉ lệ giảm bach câu, bạch câu trung tính, tiểu cầu xảy ra phổ biến hơn ở nhóm điều trị CF [7]

Đặc điểm tác dụng phụ do hóa chất trên nhóm bệnh nhân nghiên cứu của chúng tôi thấp hơn so với nghiên cứu của tác giả Nguyễn Đức Lợi có thể do chúng tôi dùng phác đồ hóa chất FOLFOX trong đó oxaliplatin được cho là độc tính thấp hơn cisplatin[8]. Chức năng thận của các bênh nhân trong nghiên cứu của chúng tôi sau điều trị đều nằm trong giới hạ bình thương, không có bệnh nhân nào bị giảm mức lọc cầu thận. Sau điều trị, có 5 bệnh nhân (15.6\%) trong nghiên cứu của chúng tôi có tình trạng tăng men gan AST, ALT ở độ 1 , có 2 bệnh nhân tăng creatinin độ 1 .

\section{KẾT LUẬN}

Hóa xạ trị đồng thời UTTQ sử dụng kĩ thuật xạ trị điều biến liều đồng thời phác đồ FOLFOX có những kết quả ban đầu khả quan về tỉ lệ đáp ứng tốt, giảm tác dụng phụ. Cân tiếp tục tiến hành nghiên cứu với số lượng bệnh nhần lớn hơn và trong thời gian theo dỗi dài hơn để thu được kết quả khách quan.

\section{TÀI LIÊU THAM KHẢO}

1. Freddie Bray, Jacques Ferlay, Isabelle SorJomataram et al (2018), Global Cancer Statistics 2018: GLOBOCAN Estimatesof Incidence and Mortality Worldwide for 36 Cancersin 185 Countries; CA Cancer J Clin 2018; 25-31.

2. Honing J, Smit JK, Muijs CT et al (2014). A comparison of carboplatin and paclitaxel with cisplatinum and 5-fluorouracil in definitive chemoradiation in esophageal cancer patients. Ann Oncol. 25(3): 638-43

3. Conroy $T$, Galais MP, Raoul $J L$, et al (2014). Definitive chemoradiotherapy with FOLFOX versus fluorouracil and cisplatin in patients with oesophageal cancer (PRODIGE5/ ACCORD17): final results of a randomised, phase 2/3 trial. Lancet Oncol . 15:305-314.

4. Clinical Practice Guidelines in Oncology (2015). Esophageal and Esophagogastric Junction cancers. NCCN Guidelines version 3.2015. 51.

5. Haefner et al (2017). Intensity - modulated versus 3 - dimensional conformal radiotherapy in the definitive treatment of esophageal cancer: comparison of outcomes and acute toxicity. Radiation Oncology. 2017; 12:13.

6. Makoto Ito, Takeshi Kodaira, Hiroyuki Tachibama et al (2017).Clinical results of definitive chemoradiotherapy for cervical esophageal cancer: Comparison of failure pattern and toxicities between intensity - modulated radiotherapy and 3 - dimensional conformal radiotherapy. Head neck.2017 Dec;39(12):2406-2415

7. Galais MP Conroy T, Raoul JL et al. (2014), Definitive chemoradiotherapy with FOLFOX versus fluorouracil and cisplatin in patient with oesophageal cancer (PRODIGE5/ACCORD17): final results of a randomised, phase $2 / 3$ trial, Lancet Oncology, 15, tr. 305-314

8. Nguyến Đức Lợi (2015) Đánh giá hiệu quả phác đồ hóa xa tri đônng thời và một số yếu tố tiên lương ung thư biểu mô thức quản giai đoan III, IV tại bệnh viện $\mathrm{K}$, Luận án tiến sĩ y khoa, Đại học Y HN.

\section{RỐI LOAN CHỨC NĂNG TÌNH DƯC Ở BÊNHH NHÂN SUY TIM CHỨC NĂNG TẦM THU THẤT TRÁI GIẢM VÀ MộT SỐ YẾU TỐ LIÊN QUAN}

Bùi Văn Nhơn ${ }^{1,2}$, Trần Tuấn Việt ${ }^{1,3}$,
Bùi Văn Tùng1, Bùi Thị Oanh ${ }^{1}$

\section{TÓM TẮT}

Muc tiêu: Mô tả tỷ lê rối loan chức năng tình dục ở bệnh nhân suy tim chức năng tâm thu thất trái giảm

\footnotetext{
${ }^{1}$ Trường Đai hoc Y Hà Nôi

²Bênh viện Đại học Y Hà Nội

${ }^{3}$ Viện Tim mạch Việt Nam

Chịu trách nhiệm chính: Bùi Văn Nhơn

Email: drbuinhon@hmu.edu.vn

Ngày nhận bài: 2/3/2021

Ngày phản biên khoa hoc: 25/3/2021

Ngày duyệt bài: 15/4/2021
}

và một số yếu tố liên quan tại Viện Tim mạch Việt Nam. Đối tượng và phương pháp: Nghiên cứu mô tả cắt ngang xác định rối loạn chức năng tình dục ở bênh nhân nữ dưa vào bộ câu hỏi FSFI, rối loan cương dương ở bệnh nhân nam dựa vào bộ câu hỏi IIEF. Kết quả: Tỷ lê suy giảm chức năng sinh duc nữ với $77,3 \%$; rối loạn cương dương ở nam $88,9 \%$; rối loan chức năng tình dục nữ và rối loạn cương dương có liên quan đến tuổibệnh nhân suy tim. Kết luận: Rối loạn chức năng tình dục nữ và rối loạn cưởng dương ở bênh nhân suy tim chức năng tâm thu thất trái giảm với tỷ lệ cao, có tương quan với tuổi của bệnh nhân suy tim. 